\title{
DETERMINANTS OF POPULATION GROWTH IN PAKISTAN
}

\author{
Shams ul Huda \\ Aga Khan University School of Nursing and Midwifery Karachi. \\ Corresponding Author Email: shamsnogram@gmail.com
}

ABSTRACT

Population growth is a major problem of developing countries, which adversely affect economic growth and development. Today world population is 7.2 billion almost double of 1960 population. Pakistan is the 6th populous country with population of 188.2 million. Population growth in Pakistan is 1.95 almost double of world population growth. Unplanned population growth results in severe shortage of resources, increase food insecurities and threaten health care system of Pakistan. Moreover, Infrastructures, roads, water and sanitation systems are deficient to meet the necessities of growing population. There are several factors which contribute in population growth including high fertility rate, inadequate family planning practices, and low income. Illiteracy, lack of political well, inefficient bureaucracy, cultural and religious back ground also has profound effect on population growth.

KEYWORDS

Population growth, Determinants of fertility, Intended pregnancies, Family planning

\section{INTRODUCTION}

Rapid population growth is a big challenge for developing countries to provide resources and amenities. In 2013 world population was around 7.2 billion, almost double of population in1960. The projected world population will be 9.4 billion till 2050. This rapid population growth started after industrial revolution in Europe, followed by decrease death rate in Asia and Africa. More than 60 percent of world populations are residing in Asia, and four among the six populous countries of the world are also in Asia. This region has growth rate of 1.3 percent as compared to world population growth of 1.1 percent. Population growth rate is define as "Increase in a country's population during a period of time, usually one year, expressed as a percentage of the population at the start of that period". It includes number of birth and death during specific period along with number of migrants from and to the country. Positive population growth indicates that population is growing; while, negative growth indicates that population is decreasing. High income countries have population growth either zero or less than one, while poorest countries have population growth more than two percent (Alex, 2012).

Currently, Pakistan population is around 188.02 million increasing with growth rate of 1.95 percent annually. The growth rate of population steadily decreases from 3.06 in 1981 to 1.95 in 2014 . Yet, Population growth rate is challenging the government initiatives to meet Millennium Developmental Goals (MDG). Population growth in Pakistan is not only higher than other neighboring countries, but also from average growth of South Asian countries. Rapid population growth put pressure on public resources and halts development of the country.

\section{Implications of rapid population growth}

Pakistan is a low income country with limited resources for public services. Unplanned population growth results in severe shortage of resources, increase food insecurities and threaten health care system of Pakistan .Less than one percent of Gross Domestic Product (GDP) is allocated for health. Scanty amount for health resulted in poor health care facilities in the country, and rise in out of pocket spending on health. Moreover, Infrastructures, roads, water and sanitation systems are deficient to meet the necessities of citizens. Growing population further depreciate the existing scares resources. According to researchers rapid population growth reduces economic growth and per capita income (Alex, 2012). Reduction in per capita income is linked with overall access to health and education. Some other investigators concludes that population growth adversely affects the economic growth; it consumed most of our resources (Afzal, 2009). Urbanization is another challenge for Pakistan, currently 38 percent population are residing in urban areas as compared to 29 percent in 1981. Rapid urbanization has resulted in suburban population with underprivileged health and education facilities. The current urban state may deteriorate, if government fails to recognize and respond the governance challenges. Rapid population growth cessation is substantial for Pakistan to continue its journey of development.

\section{Determinants of population growth}

Population growth in Pakistan has started early before the partition. There are several factors which contribute in population growth including high fertility rate, inadequate family planning (FP) practices, reduction in mortality rate, and low level of literacy particularly in women. Moreover, cultural, religious background, limited political and bureaucratic supports are also responsible of rapid population growth.

\section{Fertility rate}

Total fertility rate (TFR) is defined as "the number of children that would be born to a woman if she were to live to the end of her childbearing years" (World Bank, 2014). Fertility rate is one of the significant determinants in population growth. Pakistan current TFR is 3.8 with 4.2 in rural areas and 3.2 in urban areas (Pakistan demographic Survey [PDS], 2013). TFR of Bangladesh, Iran, and India are respectively 2.2, 1.9, and 2.5 less than TFR of Pakistan. High TFR has resulted in explosion of population growth in last several decades. TFR equal to 2.1 is considered replacement rate; fertility rate below 2.1 will decline population growth and fertility rate above 2.1 will continue persistent population growth. High TFR in Pakistan is due to unwanted and wanted fertilities. 


\section{Unwanted fertility}

Unwanted fertility is the condition in which women have more children as she desired. The numbers of unwanted pregnancies in Pakistan is $43.2 \%$; in which $15.3 \%$ ended up with abortion, $22 \%$ unintended birth and 5.9\% miscarriage (Ezeh, 2012). Population growth can be reduced by decreasing unwanted fertility. Unintended pregnancies count for 57 per 1000 in developing countries, and 42 per 1000 in developed countries (Kott, 2011; Singh, 2010). The trend in Pakistani women and men are changing and now they prefer to delay child bearing. According to DHS (2013) the numbers of women who want no more children are increasing with number of children; it is 85 percent among women who have five or more than five children. Controlling unwanted pregnancies will reduce TFR which help in reduction of Population growth.

\section{Wanted fertility}

Wanted fertility is number of births excluding unwanted birth. The current hypothesized size of ideal family for women and men are respectively $4.3 \& 4.1$. This shows the preference of both male and female for large family. Wanted fertility rate in last three years was 2.4 in urban areas and 3.1 in rural areas. This is quite lesser than the current TFR in Pakistan. Both wanted and unwanted pregnancies are higher in rural and uneducated families.

\section{Education}

Level of education directly influences the number of wanted and unwanted fertility. TFR rate decreases with increasing education. According to DHS (2013) TFR in higher educated population is 2.5 lesser than 4.4 in illiterate population. MDG two aims 100 percent primary education and 88 percent literacy (PES, 2014). Still, Pakistan is struggling for elevation of literacy and primacy education. According to PES (2014) literacy rate in male is 71 percent and in female is 48 percent with overall 60 percent. Literacy rate is also linked with contraceptive utilization. Educated women have more awareness about contraceptives and their side effects. Contraceptive usage has increased from 30 percent among women with no education to 41percent among women with primary education.

\section{Poverty}

Poverty is a state in which individual are unable to meet their essential needs. Poverty is defined in terms of income. Income less than $\$ 1.25$ per day are considered below poverty line. Currently, 21.04 percent of people are living below poverty line in Pakistan. Poverty eradication is MDG priority; however, Pakistan fails to archive it due to economic crises. Income level influence contraceptive practices, which eventually affect TFR. TFR among low socioeconomic families remain high 4.2 as compared to wealthiest families 2.8 (Agha, 2010). One reason of these difference could be women belong to wealthiest families marry later, and are knowledgeable about contraceptives. Moreover, they are independent in their decisions. According to DHS (2013) the fertility rate ranges among poor women is higher than rich women. Wealthy women have more control on decision related to pregnancies and reproductive health.

\section{Family planning}

Poor practices of FP lead to unintended and intended pregnancies. Family planning allows individuals and couples to attain their desired number of children and help them in spacing and timing of births (WHO). The prevalence of contraceptive in developing countries is 60 percent (Cleland, 2006). Such low level of contraceptive usage results in population growth. There are several reasons of non-compliance with contraceptives including availability of FP services, low level of knowledge, cost related to contraceptives, side effects of contraceptive, social and cultural issues (Bongaarts, 2013). Several methods of FP are practiced in Pakistan including modern methods, traditional methods, injectable, condom and female sterilization. However, still we are facing the issue of unmet contraceptive needs. Unmet needs refer to the percentages of women who do not want to become pregnant; however, they are not using contraception. Unmet needs of contraception are used to measure the prevalence of contraceptive in a country. Twenty percent of women have an unmet need for family planning. Poor and illiterate women have high unmet needs for family planning as compared to rich and educated women. The unmet need of contraceptive decreased from 29 percent in 1991 to 20 percent in 2012. Several factors including maternal age, educational status, and maternal autonomy have positive impact on utilization of contraceptives. The demand for contraceptive is $\mathbf{5 5}$ percent, while prevalence of contraceptive usage is 35 percent (Ali, 2014).

\section{Religious and cultural factors}

Religious and cultural factors have intense effect on utilization of FP services. In some culture in Pakistan, communication lag between spouses on FP exert negative impact on reproductive health behaviors (Azmat, 2012). This gap is usually filled by mother in law by imposing her decisions. The supportive attitude of in laws specially husband increases utilization of contraceptives. Aga (2010) concludes that women are reliant on their husbands for FP. Poor health facilities and side effects of contraception hinder the utilization of FP services. Religious beliefs have pivotal role in shaping decisions regarding contraception. Some religious scholars oppose FP practices on basis of their interpretation. However, other religious leaders support temporary method of FP. Husband's attitude along with religious oppositions count for the 50 percent reported barriers regarding FP (Stephenson, 2004). However, several studies conclude that Muslim religious leaders have resistance against permanent method of family planning. Religious scholars in Egypt support the notion of FP and encouraged temporary method of FP (Underwood, 2000).

\section{CONCLUSION AND RECOMMENDATION}

Population growth in Pakistan is more rapid as compared to other regional countries. This explosion of population inversely affects the government initiatives for development, and result in elevation of poverty. Some recommendations are suggested to tackle rapid growth of population. Population growth in Pakistan is directly related with high fertility rate, intended and unintended pregnancies are the major reasons of high fertility. Door to door awareness campaign should be initiated to reduce unmet needs of contraceptive. Quality family planning services should be provided at affordable cost. Female education and wealth have direct 
relationship with fertility rate. Women with high education and from wealthiest families have lesser fertility rate than women with no education and from poor families. Unfortunately, we have very low level of women education in South Asian region. Government should design policies to increase education particularly of females. Cultural back ground has a profound effect of fertility rate, and population growth is high in traditional societies. Similarly, some religious leaders encourage population growth, while others stress on temporary methods of FP. Involvement of religious leaders will reduce population growth in the country.

\section{Acknowledgements}

I would like to acknowledge the support and feedback of Dr. Tazeen Saeed Ali (Associate Professor) Aga Khan University School of Nursing and Midwifery (AKU-SoNAM)

\section{REFERENCES}

- Afzal, M. (2009). Population Growth and Economic Development in Pakistan. The Open Demography Journal, 2, 01-07.

- Agha, S. (2010). Intentions to use contraceptives in Pakistan: implications for behavior change campaigns. BMC public health, 10(1), 450.

- Ali, S. A. (2014). Unmet need for contraception and unintended pregnancies among women of reproductive age group: A situation analysis. El Mednifico Journal, 2(3), 259265.

- $\quad$ Azmat, S. K., Mustafa, G., Hameed, W., Ali, M., Ahmed, A., \& Bilgrami, M. (2012). Barriers and perceptions regarding different contraceptives and family planning practices amongst men and women of reproductive age in rural Pakistan: a qualitative study. Pakistan Journal of Public Health, 2(1), 17-23

- Bongaarts, J., Sathar, Z. A., \& Mahmood, A. (2013). Population trends in Pakistan. Population Council Book Series, 1(1), 13-23.

- Cleland, J., Bernstein, S., Ezeh, A., Faundes, A., Glasier, A., \& Innis, J. (2006). Family planning: the unfinished agenda. The Lancet, 368(9549), 1810-1827.

- Ezeh, Alex C., John Bongaarts, and Blessing Mberu. "Global population trends and policy options." The Lancet 380.9837 (2012): 142-148.

- Kott, A. (2011). Rates of Unintended Pregnancy Remain High In Developing Regions. International perspectives on sexual and reproductive health, 37.

- Singh, S., Sedgh, G., \& Hussain, R. (2010). Unintended pregnancy: worldwide levels, trends, and outcomes. Studies in family planning, 41(4), 241-250.

- Stephenson, R., \& Hennink, M. (2004). Barriers to family planning use amongst the urban poor in Pakistan.

- Underwood, C. (2000). Islamic precepts and family planning: The perceptions of Jordanian religious leaders and their constituents. International Family Planning Perspectives, 110-136. 